\title{
Proceeding
}

Supplementary Issue: Spring Conferences of Sports Science. 15th Convention and Workshop of the International Network of Sport and Health Science, 5-8 June 2019. University of Las Palmas de Gran Canaria, Las Palmas de Gran Canaria, Spain.

\section{Factor structure of technical preparedness of judokas of various somatic types}

\author{
ALEXANDER BOLOTIN ${ }^{1}$, VLADISLAV BAKAYEV ${ }^{1}$, VALERIYA VASILYEVA ${ }^{1}$, ALEXEY BOBRISHEV ${ }^{2}$ \\ ${ }^{1}$ Institute of Physical Education, Sports and Tourism, Peter the Great St. Petersburg Polytechnic University, \\ Russian Federation \\ ${ }^{2}$ Saint-Petersburg University of State Fire Service of Emercom of Russia, Russian Federation
}

\begin{abstract}
The study focuses on the factor structure of technical preparedness of judokas of various somatic types, as they perform throws. The study showed that judokas of microsomal type usually use techniques that require greater levels of motion coordination abilities (47.2\%), and rarely resort to power throws (19.3\%). Mesosomal type wrestlers mostly use speed and power throws (41.3\%), and rarely - throws that require high levels of movement coordination ability (25.1\%). Macrosomal type wrestlers most often use power throws (54.3\%), the least contribution into the dispersion for this type of wrestlers belongs to movement coordination type of throws (17.6\%). A total of eighteen judokas aged 16-18 of different somatic types were studied. The distribution into somatic types was carried out to determine the groups of somatic types of judokas taking part in the experiment. The subjects were distributed into three groups according to their somatic types. A total of five judokas were of MiS (microsomal) type; seven represented the MeS (mesosomal) type; and six the MaS (macrosomal) type. All three groups of judokas were required to perform throws to assess their technique. The factor analysis of technical preparedness of judokas showed that the effectiveness of their throws might be influenced by their somatic type. The study established that microsomal judokas relied the most on movement coordination and speed; mesosomal - on their perseverance, speed, and power, and macrosomal - on their power alone as the leading physical quality. Keywords: Factors; Technical preparedness; Judokas; Somatic types; Qualitative characteristics of throws.
\end{abstract}

\section{Cite this article as:}

Bolotin, A., Bakayev, V., Vasilyeva, V., \& Bobrishev, A. (2019). Factor structure of technical preparedness of judokas of various somatic types. Journal of Human Sport and Exercise, 14(4proc), S698-S705. doi:https://doi.org/10.14198/ihse.2019.14.Proc4.30

Corresponding author. Institute of Physical Education, Sports and Tourism, Peter the Great St. Petersburg Polytechnic University, Russian Federation. http://orcid.org/0000-0001-9455-9662

E-mail: vlad.bakaev@gmail.com

Supplementary Issue: Spring Conferences of Sports Science. 15th Convention and Workshop of the International Network of Sport and Health Science, 5-8 June 2019. University of Las Palmas de Gran Canaria, Las Palmas de Gran Canaria, Spain. JOURNAL OF HUMAN SPORT \& EXERCISE ISSN 1988-5202

(c) Faculty of Education. University of Alicante

doi:10.14198/jhse.2019.14.Proc4.30

S698 | 2019 | Proc4 | VOLUME 14

(C) 2019 University of Alicante 


\section{INTRODUCTION}

Wrestling competitions today require that the wrestlers are well prepared technically (Bakaev, Bolotin, \& Vasil'eva, 2015; Bolotin, \& Bakayev, 2016a; Detanico, et al., 2015; Dudnyk, et al., 2017; Bakayev, 2015; Bolotin \& Bakayev, 2018; Myers, et al., 2013; Santos, et al., 2012; Pityn, et al., 2017; Sorensen, et al., 1996; Nakonechnyi \& Galan, 2017). The degree of technical preparedness of wrestlers depends on qualitative characteristics of throws they perform. At the same time, current training strategies for athletes usually assess the systemic character of throw techniques, without any consideration of the somatic type of the athlete. These training methods that do not take into account the judokas' somatic types do not allow to prepare them for competitions adequately (Lariosa, et al., 2017; Prontenko, et al., 2017; Bakaev, Bolotin \& Aganov, 2016; Detanico, et al., 2015; Bolotin \& Bakayev, 2016b).

The objective of the study is to define the ways for improving technical preparedness of judokas of various somatic types as they performs throws.

\section{Research Objectives}

To study various aspects of technical preparedness of judokas of various somatic types, as they perform throws. To determine differences in technical preparedness of judokas of various somatic types, as they perform throws.

\section{MATERIALS AND METHODS}

A total of eighteen judokas aged 16-18 of different somatic types were studied. The distribution into somatic types was carried out to determine the groups of somatic types of judokas taking part in the experiment. The subjects were distributed into three groups according to their somatic types. A total of five judokas were of MiS (microsomal) type; seven represented the MeS (mesosomal) type; and six - the MaS (macrosomal) type.

All three groups of judokas were required to perform throws to assess their technique. The assessed parameters included:

- Types of throws that require maximum power and body mass (hip rolls, liftovers, spring throws);

- Types of throws that require speed and power abilities (pickups, trippings, flying rolls);

- Types of throws that require movement coordination abilities (leg grips, undercuts, hookings).

The study determined the factor structure of technical preparedness of judokas of various somatic types, as they perform throws. The correlation coefficient of factor load $(r)$ was assessed for every factor $(\%)$.

\section{RESULTS AND DISCUSSION}

An important indicator of sportsmanship in judokas is the mastery of wrestling skills. In the beginning of the experimental period, a research project was performed to determine the difference between the parameters of special physical conditioning for judo and the level of technical sportsmanship in athletes of various somatotypes.

Table 1 shows the results of special physical conditioning for judo in various judoka somatotypes. 
Table 1. Comparative results of special physical conditioning for judo in various judoka somatotypes

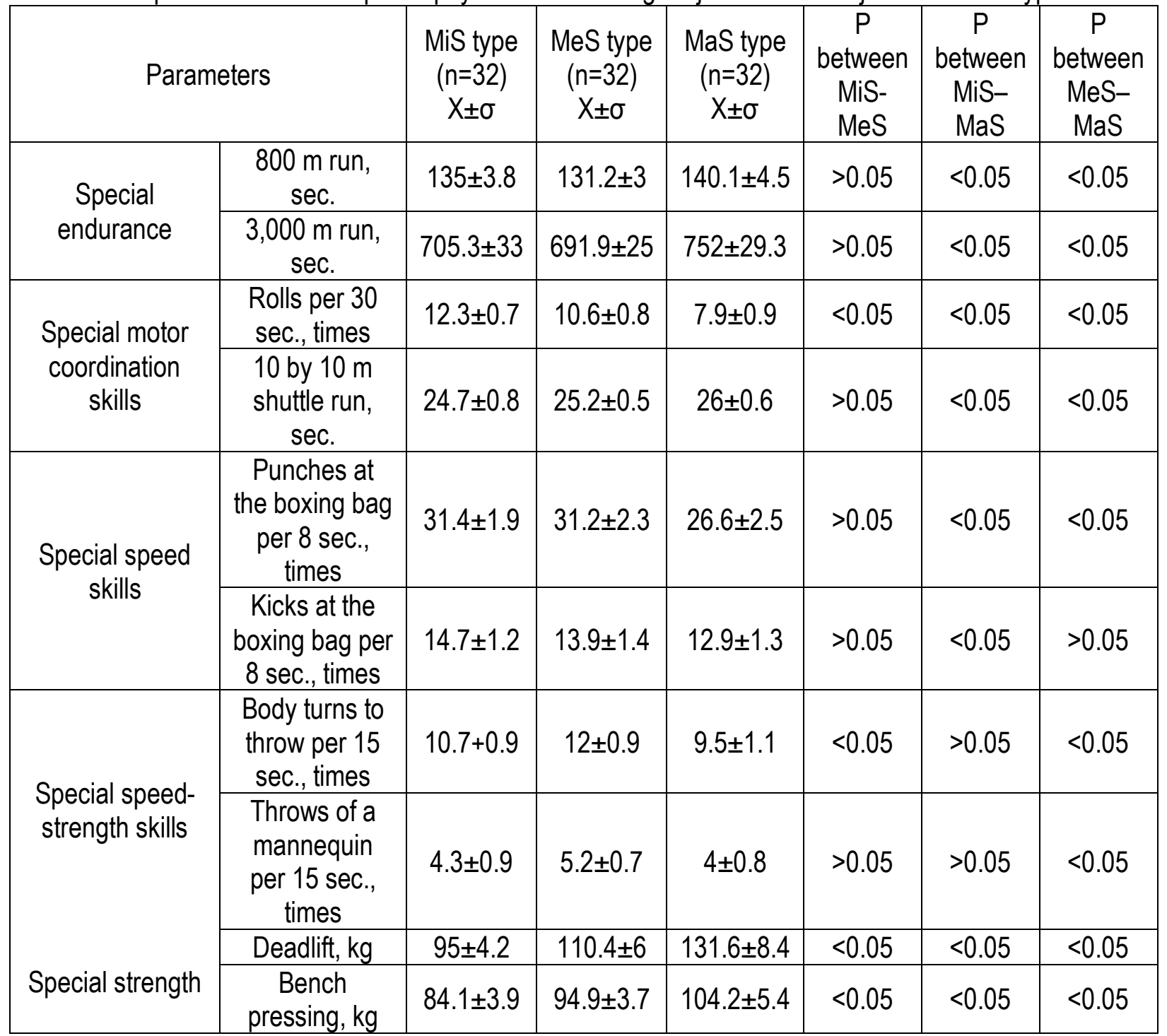

Note: MiS - microsomal type judokas; MeS - mesosomal type judokas, MaS - macrosomal type judokas.

The obtained results indicate that the microsomal type judokas have an advantage over judokas of other somatotypes in rolls per $30 \mathrm{sec}$ - 12.3 times, in 10 by $10 \mathrm{~m}$ shuttle run $-24.7 \mathrm{sec}$., in punches at the boxing bag per $8 \mathrm{sec}$. -31.4 times, in kicks at the boxing bag per $8 \mathrm{sec}$. -14.7 times; however, much lower results have been obtained for other parameters: $800 \mathrm{~m}$ run $-135 \mathrm{sec} ., 3,000 \mathrm{~m}$ run $-705.5 \mathrm{sec}$., body turns to throw per $15 \mathrm{sec}$. -10.7 times, mannequin throws per $15 \mathrm{sec}$. -4.3 times, deadlift - $95 \mathrm{~kg}$, bench pressing - $84.1 \mathrm{~kg}$. Thus, the microsomal type judokas possess higher special motor and coordination skills as compared to mesosomal and macrosomal type judokas, whereas in special endurance and special speedstrength skills they manifested average values and in strength skills scored lower than representatives of the other somatotypes.

Studying the results of special physical conditioning for judo in mesosomal type judokas shows that the representatives of this somatotype had an advantage over microsomal and macrosomal types in $800 \mathrm{~m}$ run $-131.2 \mathrm{sec}$., in 3,000 m run $-691.9 \mathrm{sec}$., in body turns to throw per $15 \mathrm{sec}$. -12 times, in mannequin throws per $15 \mathrm{sec}$. -5.2 times. Results in rolls per $30 \mathrm{sec}$. ( 10.6 times), 10 by $10 \mathrm{~m}$ shuttle run $(25.2 \mathrm{sec}$.), punches 
at the boxing bag per $8 \mathrm{sec}$. (31.2 times), kicks at the boxing bag per $8 \mathrm{sec}$. (13.9 times), deadlift (110.4 kg), bench pressing $(94.9 \mathrm{~kg})$ appeared to be somewhat lower as compared to representatives of other somatotypes. Thus, the mesosomal type judokas are more advanced in special endurance and special speed-strength skills and, respectively, are less advanced in special motor and coordination, speed and strength skills as compared to the microsomal and macrosomal somatotypes.

Macrosomal type judokas had an advantage over the microsomal and mesosomal types in deadlift (131.6 $\mathrm{kg}$ ) and bench pressing $(104.2 \mathrm{~kg})$, whereas other results of the parameters descriptive of special physical conditioning for judo scored lower than in other judoka somatotypes: $800 \mathrm{~m}$ run $-140.1 \mathrm{sec}$., $3,000 \mathrm{~m}$ run $752 \mathrm{sec}$., rolls per $30 \mathrm{sec}$. -12.3 times, 10 by $10 \mathrm{~m}$ run $-26 \mathrm{sec}$., punches at the boxing bag -26.6 times, kicks at the boxing bag per $8 \mathrm{sec} .-12.9$ times, body turns to throw per $15 \mathrm{sec}$. -9.5 times, mannequin throws per $15 \mathrm{sec} .-4$ times. The obtained data suggest that the macrosomal type judokas have an advanced level of special strength and low special endurance, special motor and coordination, speed and speed-strength skills.

Table 2 shows the results of the comparative analysis of technical sportsmanship in various judoka somatotypes. The obtained results indicate that microsomal type judokas performed better than other somatotypes in the number of attacking moves (27.5 times), in the matchup activity (9.2 attacks/min.) and in combination skills $(30.7 \%)$. The results captured for other technical conditioning parameters appeared to be somewhat lower than in the mesosomal and macrosomal type representatives: the number of scored attacking moves -10.5 times, reliability of attacking moves $-191.2 \%$. Thus, the microsomal type judokas demonstrate higher activity during matchups, perform more attacking moves and combinations as compared to representatives of other somatotypes, however their scores are average and reliability of technique is higher in mesosomal and macrosomal types.

Table 2. Comparative results of technical sportsmanship in judokas of various somatotypes

\begin{tabular}{ccccccc}
\hline Parameters & $\begin{array}{c}\text { MiS type } \\
(\mathrm{n}=32) \\
\mathrm{X} \pm \sigma\end{array}$ & $\begin{array}{c}\text { MeS type } \\
(\mathrm{n}=32) \\
\mathrm{X} \pm \sigma\end{array}$ & $\begin{array}{c}\text { MaS type } \\
(\mathrm{n}=32) \\
\mathrm{X} \pm \sigma\end{array}$ & $\begin{array}{c}\mathrm{P} \\
\text { between } \\
\text { MiS-MeS }\end{array}$ & $\begin{array}{c}\mathrm{P} \\
\text { between } \\
\text { MiS-MaS }\end{array}$ & $\begin{array}{c}\mathrm{P} \\
\text { between } \\
\text { MeS- } \\
\mathrm{MaS}\end{array}$ \\
\hline $\begin{array}{c}\text { Attacking moves, times } \\
\begin{array}{c}\text { Scored attacking } \\
\text { moves, times }\end{array}\end{array}$ & $\begin{array}{c}27.5 \pm 1.8 \\
10.5 \pm 2.7\end{array}$ & $26.3 \pm 3.1$ & $24.2 \pm 3.2$ & $>0.05$ & $<0.05$ & $>0.05$ \\
$\begin{array}{c}\text { Reliability of attacking } \\
\text { moves, \% }\end{array}$ & $191.2 \pm 46.9$ & $224.5 \pm 33.8$ & $197 \pm 49$ & $>0.05$ & $>0.05$ & $<0.05$ \\
$\begin{array}{c}\text { Activity, number of } \\
\text { attacks per minute } \\
\text { Combination skills, \% }\end{array}$ & $9.2 \pm 0.6$ & $8.8 \pm 1$ & $8.1 \pm 1.1$ & $>0.05$ & $>0.05$ & $<0.05$ \\
\hline
\end{tabular}

Note: MiS - microsomal type judokas; MeS - mesosomal type judokas, MaS - macrosomal type judokas.

The results of the evaluation of technical sportsmanship in mesosomal type judokas proved to be higher than in microsomal and microsomal types in the number of scored attacking moves (11.8 times), and in reliability of attacking moves (224.5\%). The results of the number of attacking moves (26.3 times), activity (8.8 attacks/min.), combination skills (26.5\%) appeared to be lower versus the representatives of other somatotypes. 
Thus, during a matchup with the opponent the mesosomal type judokas exhibit low combination skills and activity, expressed in lower use of attacking moves and scored attacking moves, as well as lower reliability of technique, as compared to the microsomal type.

The results of evaluation of technical sportsmanship in macrosomal type judokas show that the subjects belonging to this somatotype had the lowest results found in this research as compared to other somatotypes by such parameters as the number of attacking moves -24.2 times, number of scored attacking moves 9.2 times, activity -8.1 attacks/min., combination skills $-22.7 \%$. However, there is a certain advantage of the macrosomal type over the microsomal type in the attacking moves reliability $-19.7 \%$. The obtained data suggest that during matchups with the opponent the macrosomal type judokas exhibit low activity expressed in the low number of attacking moves and combinations, however they have average reliability of attacking moves as compared to judokas of other somatotypes.

The level of technical sportsmanship in defensive moves of judokas was determined using the expert evaluation method based on the assessment by 5 experts.

Technical sportsmanship assessment was performed in special conditions simulating various wrestling situations using a five-point scale.

The results of professional skills maturity in judokas of various somatotypes are shown in Table 3.

Table 3. Comparative results of technical sportsmanship in defensive moves for judokas of various somatotypes

\begin{tabular}{ccccccc}
\hline Parameters & $\begin{array}{c}\text { MiS type } \\
(\mathrm{n}=32) \\
\mathrm{X} \pm \sigma\end{array}$ & $\begin{array}{c}\text { MeS type } \\
(\mathrm{n}=32) \\
\mathrm{X} \pm \sigma\end{array}$ & $\begin{array}{c}\text { MaS type } \\
(\mathrm{n}=32) \\
\mathrm{X} \pm \sigma\end{array}$ & $\begin{array}{c}\text { P between } \\
\text { MiS-MeS }\end{array}$ & $\begin{array}{c}\text { P between } \\
\text { MiS-MaS }\end{array}$ & $\begin{array}{c}\text { P between } \\
\text { IMeS-MaS }\end{array}$ \\
\hline $\begin{array}{c}\text { Defensive moves in the } \\
\text { standing position, } \\
\text { points }\end{array}$ & $17.7 \pm 1.7$ & $18.6 \pm 3.2$ & $17.4 \pm 2.3$ & $>0.05$ & $>0.05$ & $>0.05$ \\
$\begin{array}{c}\text { Defensive moves in } \\
\text { grips and holds, points }\end{array}$ & $18.2 \pm 2.4$ & $18.5 \pm 2.8$ & $19.5 \pm 2.4$ & $>0.05$ & $>0.05$ & $>0.05$ \\
\hline
\end{tabular}
Note: MiS - microsomal type judokas; MeS - mesosomal type judokas, MaS -macrosomal type judokas.

The comparative analysis of the parameters under investigation showed that microsomal type judokas had an advantage over the mesosomal and macrosomal type representatives by the parameter "defensive moves in a standing position" (17.4 points), whereas other somatotypes scored higher by the remaining parameters. The obtained data suggest that the microsomal type judokas exhibit high mastery of defensive moves in a standing position in situations which, on the other hand, do not require high strength, and, on the other hand, call for advanced motor, coordination and speed skills.

The results shown in Table 3 indicate that the mesosomal type judokas outperformed other somatotypes in the situations related to demonstration of defensive moves in the standing position (18.6 points). In the meantime, the results of defensive moves in grips and holds (18.5 points) appeared to be lower than in the representatives of microsomal and macrosomal types. Thus the obtained data suggests that the mesosomal type judokas exhibit high performance in situations requiring speed-strength skills and endurance. 
In their turn, the macrosomal type judokas outperform the other somatotypes by the parameter "defensive moves in grips and holds" (19.5 points), lagging behind by all other parameters. The obtained data shows that the macrosomal type judokas exhibit high performance in defensive techniques in the situations when high strength is key. In the meantime, in the situations requiring speed, motor and coordination skills, the macrosomal type is less successful than the other judoka somatotypes.

Thus, it has been established that various somatotypes of judokas differ by the parameters of special physical conditioning and technical sportsmanship.

Competitive successes of judokas reflect the degree of their technical preparedness for competitions. To achieve best possible results, various factors of preparedness must be utilized, including adaptation to morphological characteristics of the body, physical preparedness, types of throws performed and other technical actions of judokas, which would vary for athletes of different somatic types.

Meanwhile, practice shows that the individual approach to training athletes depends on the coach's ability to define the specific factors that affect the athletes' technical preparedness. Considering these factors allows to differentiate training routines for judokas of various somatic types. Therefore, in order to study individual typological attributes of judokas of various somatic types, it was necessary to establish the factors affecting the structure of their technical preparedness.

It was established that the differences in the movement potential of judokas of various somatic types has a qualitative influence on how those or other moves, see Table 4.

Table 4. Factor structure of technical preparedness of judokas of various somatic types, as they perform throws

\begin{tabular}{|c|c|c|c|c|c|c|c|}
\hline \multirow[b]{2}{*}{ Factors } & \multirow[b]{2}{*}{ Indicators } & \multicolumn{2}{|c|}{ MiS } & \multicolumn{2}{|c|}{ MeS } & \multicolumn{2}{|c|}{ MaS } \\
\hline & & $r$ & $\begin{array}{c}\text { Factor } \\
\text { Weight } \\
(\%)\end{array}$ & $r$ & $\begin{array}{c}\text { Factor } \\
\text { Weight } \\
(\%)\end{array}$ & r & $\begin{array}{c}\text { Factor } \\
\text { Weight } \\
(\%)\end{array}$ \\
\hline \multirow{3}{*}{$\begin{array}{l}\text { Throws with } \\
\text { Movement } \\
\text { Coordination } \\
\text { Focus }\end{array}$} & $\begin{array}{l}\text { Leg Grip } \\
\text { Throws }\end{array}$ & 0.893 & \multirow{3}{*}{47.2} & 0.524 & \multirow{3}{*}{25.1} & 0.295 & \multirow{3}{*}{17.6} \\
\hline & Undercuts & 0.874 & & 0.511 & & 0.323 & \\
\hline & Hookings & 0.815 & & 0.507 & & 0,261 & \\
\hline \multirow{3}{*}{$\begin{array}{l}\text { Throws with } \\
\text { Speed and } \\
\text { Power Focus }\end{array}$} & Pickups & 0.516 & \multirow{3}{*}{33.5} & 0.828 & \multirow{3}{*}{41.3} & 0.462 & \multirow{3}{*}{28.1} \\
\hline & Flying rolls & 0.615 & & 0.802 & & 0.398 & \\
\hline & Trippings & 0.681 & & 0,863 & & 0.521 & \\
\hline \multirow{3}{*}{$\begin{array}{l}\text { Throws with } \\
\text { Power Focus }\end{array}$} & Hip rolls & 0.539 & \multirow{3}{*}{19.3} & 0.613 & \multirow{3}{*}{33.6} & 0.905 & \multirow{3}{*}{54.3} \\
\hline & Liftovers & 0.284 & & 0.705 & & 0.873 & \\
\hline & Spring throws & 0.232 & & 0.678 & & 0.868 & \\
\hline
\end{tabular}

Note: MiS - microsomal type judokas; MeS - mesosomal type judokas, MaS - macrosomal type judokas, $r$ - correlation coefficient, which determines factor loads.

Table 4 presents the results of factor analysis of preparedness of judokas of various somatic types as they perform different kinds of throws. According to the data, microsomal type judokas usually use techniques that require movement coordination abilities $(47.2 \%)$ and rarely use power throws (19.3\%). Mesosomal type wrestlers mostly use speed and power throws $(41.3 \%)$, and rarely - throws that require high levels of movement coordination ability (25.1\%). Macrosomal type wrestlers most often use power throws (54.3\%), 
the least contribution into the dispersion for this type of wrestlers belongs to movement coordination type of throws (17.6\%).

The results of the factor analysis of technical preparedness of judokas of various somatic types allowed to define the subjects' individual typological peculiarities. For instance, microsomal type athletes relied the most on movement coordination and speed; due to their lower weight as compared to other judokas and length of their arms and legs, they were best with leg grips, undercuts and hookings. Mesosomal type athletes stood out with the strong perseverance, speed and power, which made flying rolls, pickups and trippings their preferred moves. Macrosomal type athletes relied the most on their power and the advantages of their body structure (large mass, long arms and legs), which made them prefer hip rolls, liftovers, and spring throws.

\section{CONCLUSIONS}

1. The factor analysis of technical preparedness of judokas showed that the effectiveness of their throws might be influenced by their somatic type.

2. When the somatic type of a judoka is defined, individual typology can be used in their training.

3. Consideration of their somatic types allows choosing the best training routines for particular groups of judokas.

4. The study established that microsomal judokas relied the most on movement coordination and speed; mesosomal - on their perseverance, speed, and power, and macrosomal - on their power alone as the leading physical quality.

Development of these qualities in judokas of various somatic types will allow to achieve better athletic results.

\section{REFERENCES}

Bakaev, V.V., Bolotin, A.E., Aganov, S.S. (2016). Physical training complex application technology to prepare rescuers for highland operations. Teoriya i Praktika Fizicheskoy Kultury, (6), pp.6-8.

Bakayev, V. (2015). Determining the significance of practical military skills applied by the special purpose regiments of the Internal Troops of the Russian Ministry of Internal Affairs to deliver combat objectives. Journal of Physical Education and Sport, 15(4), pp. 615-618.

Bakaev, V.V., Bolotin, A.E., \& Vasil'eva, V.S. (2015). Factors determining sports specialization of cross country skiers. Teoriya i Praktika Fizicheskoy Kultury, (2), 40-41.

Bolotin A., Bakayev V. (2016a). Factors that determine high efficiency in developing speed and strength abilities of female hurdlers. Journal of Physical Education and Sport, 16(3), pp.910-913.

Bolotin A., Bakayev V. (2016b). Efficacy of using isometric exercises to prevent basketball injuries. Journal of Physical Education and Sport, 16(4), pp.1177-1185. https://doi.org/10.7752/jpes.2016.04188

Bolotin, A., \& Bakayev, V. (2018). Pedagogical practice for development of coordination potential of MMA fighters and estimation of its efficiency. Journal of Human Sport and Exercise, 13(1), 72-88. https://doi.org/10.14198/ihse.2018.131.08

Detanico, D., Dal Pupo, J., Franchini, E., \& Dos Santos, S. G. (2015). Effects of successive judo matches on fatigue and muscle damage markers. Journal of Strength and Conditioning Research, 29, 1010 1016. https://doi.org/10.1519/JSC.0000000000000746

Dudnyk O., Yarmak O., Dotsyuk L., Mykhaylyshyn G., Zoriy Y., Moseychuk J. (2017). Assessment of human psychophysiological responses to intense exercise: a survey of Greco-Roman wrestlers and 
unqualified competitors. Journal of Physical Education and Sport, 17 Supplement issue 4, 20892096. https://doi.org/10.7752/jpes.2017.s4212

Lariosa, C. Gozdowski, D., Pietkiewicz, S., \& Maciejewski, R. (2017). Survey of judo injuries in physical education classes: a retrospective analysis. Journal of Physical Education and Sport, 17(3), 20342042.

Myers, T., Nevill, A. \& Al-Nakeeb, Y. (2013). A comparison of the effect of two different judging systems on the technique selection of Muay Thai competitors. Journal of Human Sport and Exercise, 8(3), 761-777. https://doi.org/10.4100//hse.2013.83.01

Nakonechnyi I., Galan Y. (2017). Development of behavioural self-regulation of adolescents in the process of mastering martial arts. Journal of Physical Education and Sport, 17, Sup plement issue 3, 1002-1008. https://doi.org/10.7752/jpes.2017.s3154

Pityn M., Briskin Y., Perederiy A., Galan Y., Tsyhykalo O., Popova I. (2017). Sport specialists' attitude to structure and contents of theoretical preparation in sport. Journal of Physical Education and Sport, 17, Supplement issue 3, 988-994. https://doi.org/10.7752/jpes.2017.s3152

Prontenko, K., Griban, G., Prontenko, V., Bezpaliy, S., Bykova, G., Zeleniuk, O., Dvoretsky, V. (2017). Level and dynamics of functional preparedness indexes of kettlebell sportsmen. Journal of Physical Education and Sport, 17 (2). pp. 712-716.

Santos WOC, Brito CJ, Júnior EAP, Valido CN, Mendes EL, Nunes MAP, Franchini E. (2012). Cryotherapy posttraining reduces muscle damage markers in jiu-jitsu fighters. Journal of Human Sport and Exercise, 7(3), 629- 638. https://doi.org/10.4100/ihse.2012.73.03

Sorensen, H., Zacho, M., Simonsen, E. B., Dyhre-Poulsen, P., \& Klausen, K. (1996). Dynamics of the martial arts high front kick. Journal of Sports Sciences, 14(6), 483-495. https://doi.org/10.1080/02640419608727735

\section{(C) $\oplus \Theta \Theta$}

This work is licensed under a Attribution-NonCommercial-NoDerivatives 4.0 International (CC BY-NC-ND 4.0). 